\title{
Nutritional and social constraints of child labourers : A study in Bhubaneswar city
}

\author{
CHANDRASHREE LENKA
}

Received: 12.04.2014; Revised: 23.09.2014; Accepted: 05.10.2014

Author for correspondence:

CHANDRASHREE LENKA

Department of Home Science, R.D. Womens College,

BHUBANESWAR (ODISHA) INDIA

Email: 1966chandrashreelenka

@gmail.com
ABSTRACT : Child labour is one of the serious problems of the present society which ultimately harms the child physically, mentally, morally, educationally as well as socially. The present investigation was designed to study the socio-economic condition, problems of child labourers and nutritional status of child labourers working in Bhubaneswar city. Data on one hundred child labourers (8-14 years) were collected randomly with the help of personal interview-cum-questionnaire method. The results of the present investigation showed that majority of the respondents were male and 80 per cent respondents were ST, SC by caste. Most of the respondents belonged to nuclear family but having more than 6 family members. None of the respondents was illiterate and earning about Rs. 1000-2000 per month. Most of them were working for more than 8-10 hrs per day and 70 per cent of them were working because of poverty and parental force. Majority of them were non-vegetarian and were taking diet rich in calorie and low in other nutrients. Mean height and weight of the respondents was found to be less than ICMR standard irrespective of all age groups.

KEY WORDS: Child labourer, Nutritional status

— HOW TO CITE THIS PAPER : Lenka, Chandrashree (2014). Nutritional and social constraints of child labourers : A study in Bhubaneswar city. Asian J. Home Sci., 9 (2) : 422-426. 